\title{
The Governance and Management of Child Care Centres
}

\author{
Suzanne E. Maloney*
}

\begin{abstract}
This study explores the management and governance interaction in a child care setting. Globally the importance of women in the workforce and the education of young children has shone the spotlight on child care. Most child care research focuses on the education of the child. However, the management and governance of the centres can influence the staffing, resources and culture of the centre, which in turn can affect the care of the children. Further, limited government funding in the sector also heightens the need to understand the impact of management and governance. The findings, from a participant-observer research approach, highlight the tensions between the management and governance functions and that the reliance on formal systems moderate the emotional exchanges that are part of the day to day social fabric of a child care centre.
\end{abstract}

Keywords: Corporate governance; management; child care.

\section{Introduction}

Despite mounting interest in childcare provision across the globe, research in the management and governance of child care centres is sparse. Various social and economic factors have collided that have led to governments reviewing their childcare policies. The main economic factor is the importance of women in the workforce to help maintain gross domestic product (GDP) and economic growth. The fall in birth rates and an aging population mean fewer workers available. Women in the workforce also helps to reduce poverty and enhances equity between men and women (OECD, 2007). The main social factor is to promote child development. Appropriate child care can enhance a child's social and intellectual development (Leach et al., 2008). This in turn leads to a healthy and vibrant community (OECD, 2011).

The interest in childcare policy is not surprising since there is a need to provide different forms of child care that match the families' needs at a cost the community is able to bear. Over the past couple of decades the changing focus of child care has moved away from a place to 'park' children while parents work, to an expectation that a childcare facility will provide some educational content. The provision of educational content increases the cost of child care provision. Research shows that higher socio-economic families use high quality registered child care services that contain educational content rather than unregistered or child minding type services (Desplanques, 1985 in OECD (2011); U.S. Department of Labour, 1988). Most governments recognise this and over the last decade have sought to regulate more closely their child care service provision. Generally, the government

\footnotetext{
* Senior Lecturer, Faculty of Finance-Banking and Business Administration,University of Southern

Queensland, Toowoomba, Australia, 4350. E-mail: Suzanne.Maloney@usq.edu.au
} 
aim is to regulate this provision to ensure a minimum quality standard. Depending on the country, the child care provision is funded through a combination of parent and government payments. The government payments may be in the form of government subsidies to parents or direct to the child care centre providing care. The balance of payments between government and parents differs across countries. For example, the US and UK have a private (parent) responsible model with government subsides available to help those of low socio-economic standing; while Nordic countries such as Sweden place a greater emphasis on the public (government) responsibility to provide child care services (OECD, 2011). Despite the difference in philosophy between the public versus private funding of child care provision, both models decentralise to local authorities and centres, the governance and management of their facilities. According to Evers (2005) there is a trend by governments to devolve responsibility and autonomy of welfare type services, such as education, to local organisations thus increasing the need to understand the impact of local management and governance arrangements.

There is little research examining the management and governance of child care centres. Limited funding in the sector means that the effective and efficient governance and management of child care facilities is of paramount importance. Most research in the child care sector are targeted at early childhood education, learning and behaviours and most government attention is directed at funding arrangements. This leads to the question of whether the governance and management arrangements of individual centres have an effect on childcare delivery and its wider social implications. This question is addressed in this study. If we can understand the management and governance arrangements and its effects on child care we can facilitate better care for children.

Using a participant-observer approach the study explores the governance and management interaction in a child care setting. The concepts of corporate governance and management are discussed that leads to the examination of the dynamics of governance and management in a regional not-for-profit child care centre. Findings generally show that the ultimate care and education of the children of the centre are impacted by the governance and management arrangements.

The next sections consider corporate governance and management in turn. This is followed by a discussion of the corporate governance and management interaction. The child care environment and the child care setting is then described. The interaction of governance, management and the child care setting are explored in the penultimate section with the final section containing the conclusion.

\section{Corporate Governance}

Corporate governance is about how an entity is governed. Generally it is about who has the authority to make decisions. Hart (1995) attempting to provide a framework of corporate governance states that issues arise due to agency problems within an entity. That is, conflicts of interest arise between owners, managers, workers, consumers and other stake holders. In the absence of this agency problem, which is the neoclassical view of the firm, all stakeholders could be instructed to maximise profits or minimise costs and be pre- 
pared to work to deliver this aim. So there would be no need for corporate governance, as no disagreements would arise because all stakeholders accept the explicit profit maximising/expense minimising goal. However, contemporary treatment of corporate governance acknowledges that conflicts of interest do arise. That various stakeholders do have differing perceptions about the mission of the entity, how resources should be used and which stakeholder goals should be prioritised. The principle-agent theory has been used extensively to consider and explain this phenomenon. Factors considered include the costs of private information, the incentive and risk-sharing trade-off and the ability to contract to mitigate (or at least minimise) these costs. This leads to the conclusion that if an ideal comprehensive principle-agent contract could be utilised there would be no need for a corporate governance structure (Hart, 1995). All issues are set forth and resolved via the contract. However, this is idealistic and as such a corporate governance structure is needed to deal with all unknowable events that could not be contracted at the present time.

Indeed many jurisdictions understand and accept this outcome and provide statutory rules with the objective of efficient and effective corporate governance that serve the market and society. A number of countries have conducted enquiries into the governance of entities examining issues such as the reporting, decision making, accountability, and the roles of management and the board of directors. Fundamental to many of these enquiries is the separation of ownership and control of an entity. This issue, highlighted by Berle and Means (1931) acknowledges that the owners or members of an entity are not making the day-to-day decisions within the entity. So the owner/members delegate this decision making authority to the board of directors (or management committee), which in turn delegates this to management (CEO). These delegations are at the heart of the principleagent dilemma discussed above.

Further, it is important to understand that the entity itself is a separate legal entity. The entity can hold assets and take on liabilities, it can sue and be sued and can contract with others. Given its artificial nature, a system of corporate governance is needed to allow humans to make decisions for the entity. To allow this, a board of directors or management committee is formed. So corporate governance refers to the "control of corporations and to systems of accountability by those in control" (Farrar, 2008). Corporate governance legislation and an entity's own rules of association provide a minimum standard and process for decision making. In addition, there are numerous guidance statements (national codes, guidelines, best practice statements, etc) to inform participants about what is expected and reasonable. The duties of directors under the law remain unchanged over many decades, but the determination of both the subjective and objective elements of director care and diligence has changed over time with the wide spread use of the codes, guidelines and best practice statements. For example, the 1997 Asian Financial Crisis saw the creation of the Asian Roundtable on Corporate Governance in 1999; and in the wake of the 2008 global financial crisis the expectations of independent directors across all jurisdictions have increased greatly. The investment by governments and corporations across the globe in corporate governance infrastructure is testament to its importance in underpinning economic growth, value creation and good social outcomes.

The OECD Principles of Corporate Governance are widely adopted globally and are utilised to establish a set of principles in a particular jurisdiction. The principles set out 
guidelines in relation to an entity adopting an effective corporate governance framework, the rights of shareholders and key ownership functions, equitable treatment of shareholders, role of stakeholders, disclosure and transparency and the responsibilities of the board. Although not targeting not-for-profit entities, the principles have been used to establish guidelines for the governance of not-for-profit entities. For example, the Australian Institute of Company Directors (AICD) have developed Good Governance Principles and Guidance for Not-for-Profit Organisations (AICD, 2013). The ten principles put forward by the AICD are:

1. Roles and responsibility - the need for clarity;

2. Board Composition - The right group of people;

3. Purpose and strategy - An appropriate vision, purpose and set of strategies;

4. Risk - Recognition and management of appropriate risk oversight;

5. Organisation Performance - A focus on effective use of resources;

6. Board Effectiveness - Appropriate board structures and processes;

7. Integrity and Accountability - The right information at the right time;

8. Organisation Building - Build and maintain organisational capability to deliver on purpose;

9. Culture and Ethics - A healthy culture in the boardroom and throughout the organisation; and

10. Engagement - Effective stakeholder engagement.

The guidance principles are not meant to be treated as rules or all encompassing, but as the name suggests are guidance to entities and to encourage conversation around the principles. Differences in their application may be a function of entity size, their actual legal form (unincorporated association, incorporated association, co-operative, public company limited by guarantee) and other legislation that would govern their conduct (i.e. Workers' Compensation, Competition Rules, etc.). The key point is that a for-profit entity and a not-for-profit entity may have different objectives, but the frameworks that oversee their processes of decision making and accountability are similar. Members delegate to the board of directors/management committee, which in turn delegate to management. There is a separation of operational decision making with that of ownership or membership rights.

\section{Management}

It is generally accepted that the management function is to plan, organise, direct and control resources for the attainment of an entities' mission. Approaches to management 
have developed and changed over time with early work based on classical economic theory through the examination of resource allocation, labour force dynamics and pricing (eg. Philosophers such as Adam Smith and John Stuart Mill). Approaches then moved into Tayor's scientific management movement (Norton, 1967), Fayol's administrative principles (Brodie, 1967) and Weber's bureaucratic organisation (Henderson \& Parson, 1947) that contained principles of planning, organising, directing and controlling. These early approaches assumed people were rational and generally advocated the need to have clear rules and standardisation, proper training, good incentives and a focus on improving efficiency and productivity.

However, similar to the corporate governance area, the discovery that humans were not rational focused attention on the social and human factors that affect decision making. Writers such as Maslow (1970), McGregor (1960) and Argyris (1957) introduced psychological and sociological perspectives. Further, Drucker (1989) brought attention to the impact of outside forces on an entity's success. This led to the later development of the systems approach which highlights the entity as part of an open system interacting within an open external environment through the acquisition of inputs from suppliers and the selling of outputs to customers (Scott, 1992). The overall contingent nature of an entity was acknowledged by Simons (1987) and attempts to match management practices with the various situational demands including strategy, structure and environment ensued.

Further issues that have arisen under the management literature include culture, quality, leadership styles, globalisation and technology advancement. The development of management knowledge illustrates that a complex set of interrelated factors impact on an entity working towards its mission.

\section{The Corporate Governance and Management Intersec- tion}

The key question is whether the corporate governance and management functions are discreet. If not, where do they intersect? Does this intersection look different in a not-forprofit entity compared to a for-profit entity? Legislation overseeing corporate governance sets out the duties of directors and the management positions of the Chief Executive Officer $(\mathrm{CEO})$ and the Chief Financial Officer $(\mathrm{CFO})$. So in this respect, there are distinct functions for the directors and key management positions. The corporate governance literature focuses on the oversight, steering and accountability functions of the board of directors, as opposed to the operational management functions. Again this leads to a distinct difference between the corporate governance and management functions. The Higgs report suggests a distinction of the two roles:

Good corporate governance must be an aid to productivity, not an impediment. It is an integral part of ensuring successful corporate performance, but of course only a part. It remains the case that successful entrepreneurs and strong managers, held properly to account and supported by effective boards, drive wealth creation. Effective boards depend as much on behaviours and relationships as on procedures and structures (R. P. Austin, Ford, \& Ramsay, 2005). 
In the management literature the distinction is unclear. Mintzberg (1975) defines a manager as a CEO, bishop, prime minister, coach or foreman (p.54) and thus recognising that management functions are not limited to the CEO. Mintzberg goes on to argue that managers at work are not the scientific, rational, informed leaders that theory would suggest and that the plan, control and direct tasks are not readily seen in their day to day work. He puts forward an alternative framework, shown in figure 1, based on authority and status of quite complex entwined role.

Figure 1: Mintzberg's (1975) management roles (Mintzberg, 1975) Formal authority and status

$\begin{array}{lll}\text { Interpersonal roles } & \text { Informational roles } & \text { Decisional roles } \\ \text { Figurehead } & \text { Monitor } & \text { Entrepreneur } \\ \text { Leader } & \text { Disseminator } & \text { Disturbance Handler } \\ \text { Liaison } & \text { Spokesman } & \text { Resource allocator } \\ & & \text { Negotiator }\end{array}$

The roles listed could fall under the duties of the governance body or the management. The ambiguity of the responsibility of each role could undermine the effectiveness of the joint management-governance leadership model. Mintzberg (1975) argues that two or three people cannot share a single managerial role unless they can act as one entity. This prevents the division of the ten roles unless there is great communication. For example if the leadership or figurehead role is contested by both the management (i.e. CEO) and the board (i.e. chair) this could result in confusion by employees or the business community. Yet Porter (1985) suggests that strategic leadership can be provided by either the managing director or the CEO. The board clearly needs to monitor the management but does the management or the board monitor the external environment, employees, competitors, etc. As suggested by Mintzberg there needs to be clear communication. Concerns about the board's micro-management of management work (Carver, 2008) and the need for the board to help provide contacts, leadership and drive performance (Hechinger, 2005; Bowen, 1994) as distinct from just ticking the governance boxes, suggest that there is no clear formula for the division of the management and governance roles. Despite this, it is clear that directors are legally in control and therefore accountable, while managers are responsible for more of the 'doing'.

\section{The Child Care Sector}

The importance of child care is evident in the number of reports and the efforts of the OECD to track child care expenditure across countries (see OECD social family database). The public spend on child care and education relative to GDP varies across countries up to the age of three but the OECD data show that this variability decreases for child care and education for the 3-5 year old bracket. This difference could be as a result of cultural norms regarding the appropriate time a women can return to work after the birth of a 
child, the availability of extended family for child care and/or the impact of government policy on the provision of child care services. The importance of the sector is also recognised by most governments through acknowledgment they are the basic building blocks of the community which in turn make up the country. Families play a central economic role, provide support to one another and determine the beliefs and culture of the community. They are the cornerstone of protection for "individuals, households and generations" (OECD, 2011). So childcare matters. Its substance in most economies through providing stability to the workforce is reflected in the Australian example of the collapse of a private company, ABC Child Care Centres, in 2008 in the wake of the global financial crisis. The collapse led to a senate inquiry in 2009 and the use of tax payer's money to fund the private corporation for a short period of time. As well as this very public development, most governments have flagged early childhood education and care as a key area in the current economic and social agenda. The government interest into this area follows the acceptance in research of the importance of the quality of child care on a child's development (Leach et al., 2008). In fact quality of child care has been linked to social competence (Howes, 1990), cooperativeness (Howes \& Olenick, 1986); peer relations (Phillips, Mekos, Scarr, McCartney, \& Abbott-Shim, 2001), aggressive behaviour (Rosenthal, 1990) and children's cortisol measures (Dettling, Gunnar, \& Donzella, 1999). Further, the confidence and direction of the young child can be shaped by the emotional labour of the child care worker. Carers sit on the periphery of family life and their worries can contribute to lower productivity (Fernandez, 1986). The balance and/or tension between the intimate carer/child relationship and that of the professional worker overseen by formal management and governance structures could be influenced. Understanding the management and governance arrangements of child care centres could help us better address concerns in a better way; thus facilitating in turn better care for children.

The child care debate among policy makers is twofold. First, the appropriate percentage split between public and private funding. Second, whether the public funds should be paid direct to providers or indirectly through parent subsidies and rebates. The answers to these questions vary across countries. What does not vary across countries is the need for the funds to be employed effectively and efficiently. This need emphasises the importance of the management and governance mechanisms of individual child care centres to ensure the best use of limited resources. Generally, the not-for-profit sector is under-researched and has received scant attention in the management literature (Holder, 1987; Parker, 2008). Yet the expanding role of the not-for-profit sector, its value to the community, the increasing assets under management and the complex and divergent agendas make understanding its management vital (Drucker, 1989; Wheelen \& Hunger, 2000; Parker, 2008). Specifically, the management and governance of the child care sector has fared even worse for attention in the management and governance literature. It is for this reason that this study focuses on the management and governance interaction of a not-for-profit child care centre. 


\section{Research Method}

This study employs a complete member researcher participant-observation approach of a non-for profit child care centre. It involved the researcher in direct, on-going contact as a member of the management committee engaged in real tasks, processes and decision making, focusing on the interactions of the director and the management committee (Ferreira \& Merchant, 1992). Data for the one-year-long ethnographic case study (Glesne, Peshkin, et al., 1992) was collected via committee meetings, interactions with staff and parents of the centre, and with discussions of members of a number of management committees in the region. The methodology employed considered the obligations, expectations and interactions of those involved with the entity in order to understand and explain the management and governance processes employed in undertaking strategic and operational tasks. The focus was on governance and management through an examination of agendas, interactions, activities and the contexts within which these interactions occurred.

The primary field site was a small not-for-profit child care centre in a large regional city in Australia. The researcher had the opportunity to gain access to the not-for-profit centre as she had two children attending the centre and was elected to the management committee. Accordingly the researcher shared in the work and experiences of management committee members as she was immersed in the management committee role (Adler \& Adler, 1987). Multiple data collection sources included agenda papers, committee minutes, reports, budget documentation, internal management reports, procedure manuals and presentations, and reflection notes on meetings and informal interactions. Data analysis focused upon the management and governance themes with a view to understanding relationships and interactions within the socio-economic context of the non-for-profit child care centre.

Inherent in the qualitative method and analysis adopted is the reflexive process in which the researcher is involved. The method openly acknowledges that the researcher could impact on the outcome by recognising that they are a part of the reflective loop of the participants by virtue of their membership of the committee. Strategies to moderate reflexivity included the keeping of journal notes and a time lapse between data collection and data analysis and write-up (Parker, 2008).

\section{The Child Care Case Study}

As is typical for a not-for-profit child care centre it was an incorporated association and as such was governed by a management committee. The management committee were elected from members of the association which were the parents of the children attending the centre. The association's incorporation meant that it was governed by the incorporated associations act administered by a state government agency. The association's rules plus the act set out the authority, responsibility and procedures to which the association has to comply. The governance rules, by virtue of the incorporated associations act, added to the highly regulated environment. This included regulation for accrediting, licensing and providing education and child care, as well as regulation such as workplace health and 
safely and industrial and child protection legislation. Thus the amount of legislation and regulation that members of the management committee had to be familiar was significant.

The six member management committee were elected from the members of the association at the annual general meeting. Members of the association were parents of children attending the centre. The rules of association were updated in 2008 to reflect the model rules set out in the Associations Incorporations Act. The centre enrolled approximately 110 children utilising 64 child care places covering the 3 months to 5 years age group. Approximately 22 staff were employed at the centre.

The rules of the association and the Associations Incorporations Act set out the authority and duties of the management committee. In general terms, these duties and authority given to a management committee of an incorporated association mirror those given to a board of directors of an incorporated company. This means that corporate governance principles apply equally to incorporated associations as they do to corporations. Where there is the absence of explicit recognition in the legislation of these duties in other jurisdictions, common law and equitable principles normally apply. Therefore the duties of management committee members are analogous to those of company directors.

The management function of a not-for-profit child care centre is undertaken by the director of that centre. This position would be analogous to the chief executive officer (CEO) of a private corporate entity. The state child care licensing regulations explicitly use the term 'director' to mean the person in charge of the centre and outline their duties in relation to the centre, children and staff. These are operational in nature and include issues such as hygiene requirements, staff to children ratios, training and education requirements of staff in certain positions and documentation requirements. As per the legislative requirements, for-profit child care entities which normally have a number of centres, would employ a director per centre to undertake these duties. They would employ a top management structure that would centrally manage finance, strategy, marketing, debt collection, human resource management and information technology requirements. However, in the not-for-profit child care centre the director was expected to take on these higher level management functions. The absence of any top management structure, and the voluntary nature of the management committee members led to this expectation, which would be the normal expectation in a non-profit child care centre.

\section{Corporate Governance, Management and Child Care}

\section{Management: Mintzberg's Management Roles}

The management committee members were volunteer members elected from parents of the centre. This had a number of implications that relate to Mintzberg's management roles. Firstly, their tenure was short term. This meant that the interpersonal and information roles tended to be the responsibility of the director of the centre. As the most senior member of long term staff, the director tended to take on the figurehead, leader, liaison, monitor, disseminator and spokesperson roles. However, the responsibility for Mintzberg's decisional roles fell in a grey area. The management committee quite often were taking on the role of disturbance handler, resource allocator, negotiator and entrepreneur. Given 
the decision making capacity of the management committee and their authority under the legislation this seemed quite a suitable arrangement. However, the types of issues that were being negotiated and handled by the management committee tended to be operational rather than strategic. So over time, the short term committee fell victim to the more urgent operational demands - demands that may never arise if time was dedicated to longer term planning.

Secondly, the time volunteer members can dedicate to the centre is limited. This impacted on the committee's effectiveness at strategic planning. The committee over the course of their tenure did try to address this by changing the format of the director's report to the committee to include more fundamental business information to allow the committee to satisfy themselves that legal obligations were being met. The report tended to include more chatty comments about students and staff. This helped to communicate a sense of the culture of the centre and was nice to have, but not essential information for the management committee. Further, the committee changed the budget reporting and put in place formal budget delegations to the director. The objective was to give the director authority to spend to a set limit without needing the formal approval of the committee. The intent was to communicate the committee's trust in the director, and to limit meeting time being taken up with small budget items. Both these measures worked to some degree.

The above examples highlight the difficulty in separating the roles in a small child care centre. The explicit role recognition for a child care centre director is contained in the child care legislation and is based on child care educational qualifications and the duties to the children. The explicit role recognition for a child care centre management committee is based in the associated incorporations legislation and sets out duties to the members (i.e. parents) of the association. This means that strategic matters are often overlooked and the contractual arrangements between the committee and director are limited to that in the child care director wage and salary award. To deviate from that may result in a breach of the award. With director duties listed in the child care legislation and the salary payment set out in the wage and salary award, any extra duties performed (such as HR, budgeting, etc) by the director falls in a grey area. Duties that any normal business would need such as budgeting, promotion, IT development, HR and debt collection, fell on the shoulders of the director without any explicit requirement in the award. In for-profit centres these functions would be performed by a central management.

The above exacerbated the reliance of the director on the management committee to help with operational matters. This had both positive and negative consequences. Firstly, the observation of staff and parents that the management committee dealt with operational matters increased staff and parents expectations that individual management committee members could step in and correct a perceived wrong. The management committee members were parents of the centre and although this gave them a unique closeness to the centre and a visceral feel of the centre culture, it also resulted in a type of entrapment of the trifling disagreements of both staff and parents. Secondly, it undermined the desired message to the child care community that the management committee had authority as a committee and not as individuals on the committee. This is a key governance principle. However, the uniqueness of being part of a group that was both the employer of centre staff and a customer and the inherent conflict of that was never properly recognised. 
Further to the above, is the warning from Chait (in (Peterson, 2009)) that the "board should suggest what the CEO should ponder, not just ponder what the CEO suggests" (Peterson, 2009). The limited time meant that the management committee tended to be handling as a priority those issues that were urgent for the director. Over time the management committee did turn this around once significant time was invested in changed systems and processes.

\section{Governance: Oversight and accountability}

Oversight and accountability were the functions most aligned to the governance role. The management, formed from members of the association (i.e. parents of the centre), are entrusted to make good long term decisions in the interest of the association as a whole. Two matters are evident for the case study committee. Firstly, the committee should be held to account for short-termism, or for acting in the interest of key members in the present time period. The incorporated association is a going concern and its interest in perpetuity should be a driving factor behind management committee decisions. Secondly, there is no independent member. In the private sector significant attention has been paid to the value of independent directors and their role in improving accountability. The addition of an independent director is prohibited by the rules of the association (only members can be management committee members). This is a key area where policy change could help small not-for-profit child care centres and would help bring a watchdog function to the committee to assist them meet their accountability requirement.

Further, of significant risk to accountability is the volunteer nature of the membership status of the management committee. Courts tend to be "reluctant to hold volunteers accountable to a high standard" (p.41) according to Bowen (1994). This release from a "high standard' may result in poor implementation and attention to the mission of the association and the safeguarding of assets and to accountability. A board member's busyness can also impede a member's contribution (Jiraporn, Singh, \& Lee, 2009). The agenda and interactions of this not-for profit management committee show that the background knowledge and expertise of the individual members of the management committee meant that there was a high degree of awareness of their obligations. This resulted in a greater transparency and discussion of accountability at management committee meetings. At the beginning of the term of governance there was a greater reliance on the director (management) to ensure proper systems and procedures were in place. However, the increasing number of operational issues drove the management committee to formulate processes and procedures relating to staffing, debtor management and child room movements. These were structural operational decisions that would normally be the responsibility of the CEO. This suggests that 1) board knowledge and expertise and 2) escalating issues are the driving factors that will result in a trade-off between volunteer time and the need to meet accountability obligations.

A key factor in the time trade-off decision for the volunteer management committee was the time given to the director to undertake the significant duties required. As indicated previously, a director is responsible under the state child care legislation, of which the focus is on child care education training, not on management training. The overseeing of the 
regulatory requirements, such as staff/student ratios, educational programmes, collection of fees and application of government funding subsidies, was a priority for the director. This left little time to develop appropriate systems or compile budgets or reports for the management committee. Light (2004) emphasises that non-profit organisations are under resourced and that "the nation wants more of virtually everything that non-profits deliver, but with no administration" (p.1). For-profit centres do not expect this extra work from their directors as their central corporate structure assumed these duties. It was apparent throughout the year that the lack of recognition of this extra administrative burden added to the ambiguity of the management and governance function.

A. M. Austin and Morrow (1985) found that directors who do not own their child care centre found 'general responsibilities' of concern compared to those that did own their centre. Further the emotional exhaustion was highest among directors and lowest among assistant teachers (Stremmel, Benson, \& Powell, 1993). The "director sets the tone of the centre, creates the environment of concern, and influences the work environment of the teachers who, in turn, provide the crucial link to children" (Mullis, Cornille, Mullis, \& Taliano, 2003). Director management training is therefore essential to ensure functions are carried out with confidence and do not overburden and cause burn out. Mullis et al. (2003) argue that directors often experience high levels of stress due to their lack of administration training and their juggling of multiple roles.

The management committee and director in this case worked through the frustrations of the administration ambiguity by focusing on their commitment to the ideals of the centre. This supports Steane (2001) who argues that not-for-profits tend to have more divergent practices due in part to their unique characteristics and their value or ideological foundations. In other words, homogeneity of governance practice should not be expected. Standardised governance practices tend to be focused on accountability upward to funders rather than to the beneficiary of services (members and children) according to Collier (2008). This is supported by Ebrahim (2009) who contends that external accountability for disclosure, accreditation and registration required by regulators and funders result in the neglect of internal accountability of "issues that are internal to organisation and individuals, such as integrity and mission" (p. 890). This was obvious in the child care setting.

Another area of neglect of regulators and funding bodies is the social capital contributed by the volunteer members of the management committee. The governance mechanism of any organisation would have a significant impact on its workings and its success, yet at no point during the year did any government agency request a meeting with the management committee or seek to view its mission or strategic/business plan. Given the significant government funding the centre received it seemed remiss not to assess the appropriateness of the plan and the form and character of the committee given the committee's impact on the culture of the centre. This cognitive social capital, according to Bryce (2012) is special to not-for-profit organisations and as such should be considered in policy decisions. Indeed, it would seem an important consideration to ensure the government dollar on child care is being used wisely.

The historical government focus on child/staff ratios, staff qualifications and the basic education of children have probably resulted in this lost opportunity for the government 
to assess the true contributions of the centre to the community. Roy, Jacko, and Edie (2008) argue that the use of volunteer knowledge, perspectives and experience is a precious resource and Quarter and Richmond (2001) maintain that there is a need to account for such social capital. The value of the not-for-profit sector is undisputed (Anheier, 2009). Government accounting for the resources contributed and the benefits gained would help set benchmarks in the private-public partnership of delivering child care.

\section{Governance: Financial Accountability}

Good financial accountability is necessary for any successful entity (Birt et al., 2008). In the private corporate sector the legislation sets out specific duties for the chief financial officer, and in the public sector specific financial responsibilities are explicit in the relevant act. In the case of the child care centre, in the associations incorporations act there is a requirement for a treasurer, and their obligations are specified. Bowen (1994) argues that this is an area where not-for-profits generally lack high level knowledge and skills. This factor together with the volunteer nature of the committee and the lack of funding for administration means that financial accountability is high risk.

The finances in the child care centre of this study were controlled by a part time bookkeeper who was a past treasurer of the management committee. The bookkeeper collected all of the source documents, completed transactions in a MYOB software package and provided a monthly report to the director. The source documents and the accounting files were kept off-site at the bookkeeper's residence. This proved problematic for both the director and the management committee members. The director found it difficult to attend to enquiries from parents, suppliers or employees about their accounts. Management committee members found it difficult to fully appreciate whether obligations to employees, creditors and government were being met and accounted for appropriately. Interactions between the bookkeeper and the director/management committee members tended to be frustrated by the lack of information. The bookkeeper guarded her documentation and records. This was the subject of discussion at a number of committee meetings. Possible reasons put forward for the tight control were the need for the bookkeeper to ensure completeness and accuracy of the accounts, and/or the need for the bookkeeper to maintain power and control over such a vital administration system thus keeping her employment secure. Discussion with other management committee members from other centres and the Creche and Kindergarten Association suggest this is not an uncommon occurrence. In the end the management committee, upon a fee increase application by the bookkeeper, made a decision based on cost to change the finance administration arrangement. Comparing the cost of the current part time bookkeeper to the option of hiring a junior administration clerk whilst outsourcing the higher level accounting functions to a local accounting firm, showed that the latter option was more cost effective. This decision meant that all records were maintained at the child care site and accessible to all those who needed them.

Further, there was no strategic financial management of resources. The management committee were obligated to consider the future of the centre. Longer range plans and cash flow forecasting would also help the centre's efficiency and effectiveness. The lack of strategic planning in the centre seemed to be a function of time. The committee had to 
deal with quite a number of operational issues (for example, the bookkeeping discussed above) that consumed the time available to the detriment of more long term thinking. An additional factor would be the short term of governance that the management committee members were committed for. In this case, one year. This put a heightened emphasis on succession planning.

\section{Conclusion}

The purpose of this paper was to examine the interaction between governance and management in action. The setting of a child care centre was chosen to address the paucity of research in the not-for profit area, and the lack of any research in the micro-level management and governance of child care centres. Child care provision is a key government and society concern. The author's membership on the management committee provided an opportunity rarely acquired to undertake a participant observer research approach to flesh out themes and factors that impinge on the workings of management and governance of child care centres. The analysis contributed to our understanding and highlighted where change is necessary to help ensure better use of resources and in turn better child care. This understanding and change is called for by Whitehead (2000):

Despite the blurring of boundaries between non-for-profit organisations and government and business, it is clear to me that not-for-profit management is distinctive in a variety of ways, ....the nature of their service mission, the scope of their funding sources, their mix of paid and volunteer labour, their governance by volunteer boards, and their role in advocacy for social change are key factors that call for separate attention in academic programming (p.82)."

Recommendations for change emanating from the results and discussion above include:

1. Better accounting to the public of the true cost of child care provision to the community. This means accounting for the social capital accrued, as well as the dollar cost expended. This in turn will allow a proper account of benefits delivered.

2. The need to provide training and resources to child care centre directors on leadership and management. This should reduce the reported burn out and stress of directors, increase their confidence which in turn would impact positively on the culture of the centre and thus on the ultimate care of our children.

3. The development of a framework to enable a childcare centre/community to assess the fulfilment of their governance and management obligations. This will reduce personal risk for management committee members and highlight areas where work is to be done.

4. To support further research in the area of governance and management of child care centres to help our understanding of this industry and ensure that limited resources are being utilised effectively. 
5. To consider the inclusion of an independent member on the management committee. This is in line with contemporary practice in the private sector and would improve management committee accountability.

6. Free training to management committee members. This could be twofold. Firstly, to ensure committee members are aware of their governance obligations and secondly, management and leadership training. Management committee members undergoing training would improve the operations of the committee and in turn the centre's effectiveness. It would also act as an incentive for members to volunteer as they would receive some type of formal certification of new skills and knowledge gained.

This research used a participant observer approach in one child care setting. Whilst suitable to the research aims, inherent in the approach are limitations. Firstly, care must be taken with generalisation. Secondly, it is acknowledged that the researcher as participant observer could impact on the outcome as they enter the reflective and decision making loop of all participants. These limitations open up areas for future research. The use of focus groups or survey research methods building on the themes identified in this paper would further develop our understanding of governance and management practices in child care centres. The application of different theoretical frameworks, such as stakeholder theory, would also provide a fresh lens to aid understanding.

Attention in the childcare setting tends to focus on funding or the educational programmes and outcomes for children. This research has plugged a gap by examining at the micro-level the governance and management of a child care centre. Children are very valuable members of any community and as such it is of paramount importance that those charged with their care are held to the highest possible standard of integrity to give the community and government confidence that children are being cared for appropriately. 


\section{References}

Adler, P. A., \& Adler, P. (1987). Membership roles in field research (Vol. 6). Sage, United States.

Anheier, H. K. (2009). What kind of nonprofit sector, what kind of society? Comparative policy reflections. American Behavioral Scientist, 52(7), 1082-1094.

Argyris, C. (1957). Personality and organisation. Harper \& Row, New York.

Austin, A. M., \& Morrow, S. C. (1985). Concerns of child care administrators as modified by education, experience, and ownership of facility. Educational Research Quarterly, 10(2), 25-30.

Austin, R. P., Ford, H., \& Ramsay, I. (2005). Company directors: principles of law and corporate governance. Retrieved from http://papers.ssrn.com/sol3/papers.cfm ?abstract_id $=922641$

Berle, A. A., \& Means, G. G. C. (1931). The Modern Corporation and Private Property. Transaction Publisher, London.

Birt, J., Chalmers, K., Beal, D., Brooks, A., Byrne, S., \& Oliver, J. (2008). Accounting: Business reporting for decision making. John Wiley \& Sons Australia, Ltd.

Bowen, W. G. (1994). When a business leader joins a nonprofit board. Harvard Business Review, 72(5), 38-48.

Brodie, M. B. (1967). Fayol on administration. Lyon, Grant and Green, London.

Bryce, H. (2012). Players in the public policy process: Nonprofits as social capital and agents. PALGRAVE MACMILLAN, United States.

Carver, M. (2008). Ten questions to ask when invited to join a board. Nonprofit World, 26(5), 20-22.

Collier, P. M. (2008). Stakeholder accountability: A field study of the implementation of a governance improvement plan. Accounting, Auditing 86 Accountability Journal, $21(7), 933-954$.

Dettling, A. C., Gunnar, M. R., \& Donzella, B. (1999). Cortisol levels of young children in full-day childcare centers: Relations with age and temperament. Psychoneuroendocrinology, 24(5), 519-536.

Drucker, P. F. (1989). What business can learn from nonprofits. Harvard Business Review, $67(4), 88-93$.

Ebrahim, A. (2009). Placing the normative logics of accountability in "thick" perspective. American Behavioral Scientist, 52(6), 885-904.

Evers, A. (2005). Mixed welfare systems and hybrid organizations: Changes in the governance and provision of social services. International Journal of Public Administration, $28(9-10), 737-748$.

Farrar, J. (2008). Corporate governance: theories, principles and practice. Oxford University Press, United States.

Fernandez, J. P. (1986). Child care and corporate productivity: Resolving family/work conflicts. Lexington Books, Lexington, MA.

Ferreira, L. D., \& Merchant, K. A. (1992). Field research in management accounting and control: a review and evaluation. Accounting, Auditing 85 Accountability Journal, $5(4), 3-34$. 
Glesne, C., Peshkin, A., et al. (1992). Becoming qualitative researchers: An introduction. Longman White Plains, New York.

Hart, O. (1995). Corporate governance: Some theory and implications. The Economic Journal, 105(430), 678-689.

Hechinger, D. (2005). Great boards make a real difference. Trusts and Estates-Atlanta, $144(10), 46-59$.

Henderson, A. M., \& Parson, T. (1947). Max weber: The theory of social economic organisation. Free Press, New York.

Holder, W. W. (1987). The not-for-profit organization financial reporting entity: An exploratory study of current practice. Financial Accountability $\&$ Management, 3(34), 311-330.

Howes, C. (1990). Can the age of entry into child care and the quality of child care predict adjustment in kindergarten? Developmental Psychology, 26(2), 292-299.

Howes, C., \& Olenick, M. (1986). Family and child care influences on toddler's compliance. Child Development, 57(1), 202-216.

Jiraporn, P., Singh, M., \& Lee, C. I. (2009). Ineffective corporate governance: Director busyness and board committee memberships. Journal of Banking \& Finance, 33(5), 819-828.

Leach, P., Barnes, J., Malmberg, L.-E., Sylva, K., Stein, A., \& the FCCC team 1. (2008). The quality of different types of child care at 10 and 18 months: A comparison between types and factors related to quality. Early Child Development and Care, $178(2), 177-209$.

Light, P. C. (2004). Sustaining nonprofit performance: The case for capacity building and the evidence to support it. Brookings Institution Press, Washington DC.

Maslow, A. H. (1970). Motivation and personality (2nd ed.). Harper \& Row, New York.

McGregor, D. (1960). The human side of enterprise. McGraw-Hill, New York.

Mintzberg, H. (1975). The manager's job: Folklore and fact. Harvard Business Review, London.

Mullis, A., Cornille, T., Mullis, R., \& Taliano, K. (2003). Childcare center directors' perceptions of their work environments: a comparison of for-profit and non-profit programs. Early Child Development and Care, 173(5), 545-556.

Norton, W. W. (1967). The principles of scientific management. Harper \& Brothers.

OECD. (2007). Babies and bosses: Reconciling work and family life: A synthesis of findings for OECD countries. Publications de l'OCDE, France.

OECD. (2011). Doing Better for Families. Publications de l'OCDE, France.

Parker, L. D. (2008). Boardroom operational and financial control: An insider view. British Journal of Management, 19(1), 65-88.

Peterson, A. H. (2009). Sleepless nights. Credit Union Magazine(March), 48-50.

Phillips, D., Mekos, D., Scarr, S., McCartney, K., \& Abbott-Shim, M. (2001). Within and beyond the classroom door: Assessing quality in child care centers. Early Childhood Research Quarterly, 15(4), 475-496.

Porter, M. E. (1985). Competitive Advantage: Creating and sustaining superior performance. New York: FreePress. 
Quarter, J., \& Richmond, B. J. B. (2001). Accounting for social value in nonprofits and for-profits. Nonprofit Management and Leadership, 12(1), 75-85.

Rosenthal, M. K. (1990). Social policy and its effects on the daily experiences of infants and toddlers in family day care in Israel. Journal of Applied Developmental Psychology, $11(1), 85-104$.

Roy, W., Jacko, V., \& Edie, D. (2008). Leading and managing governance change. Nonprofit World, 26(3), 28-39.

Scott, W. R. (1992). Organizations: Rational, natural, and open systems (Prentice Hall, Upper Saddles River. ed.). Prentice Hall, Upper Saddles River.

Simons, R. (1987). Accounting control systems and business strategy: An empirical analysis. Accounting, Organizations and Society, 12(4), 357-374.

Steane, P. (2001). Governance: Convergent expectations, divergent practices. Corporate Governance: The International Journal of Business in Society, 1(3), 15-19.

Stremmel, A. J., Benson, M. J., \& Powell, D. R. (1993). Communication, satisfaction, and emotional exhaustion among child care center staff: Directors, teachers, and assistant teachers. Early Childhood Research Quarterly, 8(2), 221-233.

Wheelen, T. L., \& Hunger, J. D. (2000). Strategic Management and Business PolicyEntering 21st Century Global Society, 7-th edition. Prentice-Hall, New Jersey.

Whitehead, J. C. (2000). Not-for-profits: An underdeveloped asset for America. Proceedings of the American Philosophical Society, 144(1), 77-82. 